\title{
Hereditary transthyretin amyloidosis overview
}

\author{
Fiore Manganelli ${ }^{1}$ (D) $\cdot$ Gian Maria Fabrizi ${ }^{2} \cdot$ Marco Luigetti $^{3,4} \cdot$ Paola Mandich $^{5,6} \cdot$ Anna Mazzeo $^{7} \cdot$ Davide Pareyson $^{8}$
}

Received: 14 September 2020 / Accepted: 5 November 2020 / Published online: 14 November 2020

(C) The Author(s) 2020

\begin{abstract}
Hereditary amyloidogenic transthyretin (ATTRv) amyloidosis is a rare autosomal dominantly inherited disorder caused by mutations in the transthyretin (TTR) gene. The pathogenetic model of ATTRv amyloidosis indicates that amyloidogenic, usually missense, mutations destabilize the native TTR favouring the dissociation of the tetramer into partially unfolded species that selfassemble into amyloid fibrils. Amyloid deposits and monomer-oligomer toxicity are the basis of multisystemic ATTRv clinical involvement. Peripheral nervous system (autonomic and somatic) and heart are the most affected sites. In the last decades, a better knowledge of pathomechanisms underlying the disease led to develop novel and promising drugs that are rapidly changing the natural history of ATTRv amyloidosis. Thus, clinicians face the challenge of timely diagnosis for addressing patients to appropriate treatment. As well, the progressive nature of ATTRv raises the issue of presymptomatic testing and risk management of carriers. The main aim of this review was to focus on what we know about ATTRv so far, from pathogenesis to clinical manifestations, diagnosis and hence patient's monitoring and treatment, and from presymptomatic testing to management of carriers.
\end{abstract}

Keywords Transthyretin $\cdot$ TTR $\cdot$ ATTRv $\cdot$ Amyloidosis

\section{Introduction}

Hereditary amyloidogenic transthyretin (ATTRv; v for "variant") amyloidosis is caused by mutations in the transthyretin (TTR) gene and is an autosomal dominantly inherited, debilitating, progressive and, if left untreated, fatal multisystem disorder. Prevalence of the disease is highly variable between

Gian Maria Fabrizi, Marco Luigetti, Paola Mandich, Anna Mazzeo and Davide Pareyson are in alphabetical order and contributed equally to this manuscript

Fiore Manganelli

fioremanganelli@gmail.com; fiore.manganelli@unina.it

1 Department of Neurosciences, Reproductive Sciences and Odontostomatology, University of Naples "Federico II", Via S. Pansini, 5, 80131 Naples, Italy

2 Section of Neurology, Department of Neuroscience, Biomedicine and Movement Sciences, University of Verona, Verona, Italy

3 Fondazione Policlinico Universitario A. Gemelli. UOC Neurologia, Rome, Italy

4 Dipartimento di Neuroscienze, Università Cattolica del Sacro Cuore, Rome, Italy the endemic and non-endemic countries and the global prevalence was estimated to be 10,186 persons (range 5526$38,468)[1]$.

The main aim of this review is to provide an overview on ATTRv amyloidosis from pathogenesis to clinical manifestations, diagnosis and hence patient's monitoring and treatment and from presymptomatic testing to management of carriers.
5 Department of Neuroscience, Rehabilitation, Ophthalmology, Genetics and Maternal and Child Health (DINOGMI), University of Genoa, Genova, Italy

6 IRCCS Policlinico San Martino, Genoa, Italy

7 Unit of Neurology and Neuromuscular Diseases, Department of Clinical and Experimental Medicine, University of Messina, Messina, Italy

8 Rare Neurodegenerative and Neurometabolic Diseases Unit, Department of Clinical Neurosciences, Fondazione IRCCS Istituto Neurologico Carlo Besta, Milan, Italy 


\section{From protein to pathology}

TTR is a homotetrameric protein with a backup carrier role of thyroxine (T4) in the plasma and cerebrospinal fluid, and by associating with the retinol-binding protein, it also mediates the transport of vitamin A. It is encoded by a small gene (chromosome 18q12.1) comprising only four exons. The monomers, formed after the cleavage of a 20 amino acid signal peptide, are composed of 127 amino acids arranged in eight antiparallel $\beta$-sheets; traditionally, the amino acid numbering refers to the mature protein. The homotetramer contains two T4-binding sites and binding of $\mathrm{T} 4$ contributes to its structural stability. Mutant and wild-type TTR may give rise in various tissues and organs to extracellular amyloid deposits formed by bundles of $\beta$-sheet fibrillar protein identified by apple-green birefringence under a polarized light microscope, after staining with Congo red, and by rigid unbranched fibrils $10-12 \mathrm{~nm}$ in diameter on electron microscopy [2].

TTR amyloidosis is a conformational disease and the pathologic protein aggregation is largely due to reduced folding stability. The pathogenetic model of ATTRv amyloidosis indicates that amyloidogenic, usually missense, mutations destabilize the native TTR favouring the dissociation of the tetramer into partially unfolded species that self-assemble into amyloid fibrils. The amyloidogenic potential of TTR variants correlates inversely with their thermodynamic stability.

Among over 130 mutations identified, the vast majority are pathogenic; a minority non-amyloidogenic, exceptional variants are protective in compound heterozygosity with pathogenic mutations.

Small molecule drugs such as tafamidis act as TTR stabilizers binding to unoccupied T4-binding sites. In ATTRv, amyloid deposits occur prevalently in the somatic and autonomic peripheral nervous system (PNS) and heart, though they may also involve kidneys, eyes, leptomeningeal vessels, joints and ligaments. This tissue specificity is elusive; endogenous factors such as glycosaminoglycans or the chemicophysical milieu might promote the amyloid deposition [3]. Due to the amyloidogenic potential of the wild-type monomers, ATTR amyloidosis may also be a non-hereditary (ATTRwt) disease, manifesting mainly as a cardiomyopathy in elderly men. Partial misfolding of the native wild-type TTR might be favoured by local chemico-physical factors [4]. An alternative pathogenetic model for ATTR amyloidosis involves mechano-enzymatic cleavages by trypsin and/or plasmin and biomechanical forces such as the shear stress by fluid flows that might be relevant particularly for cardiomyopathy [5].

The heterogeneity of the amyloidogenic pathways may explain the distinct biochemical composition of amyloid fibrils which are formed by $\mathrm{C}$-terminal fragments (type A fibrils) in ATTRwt and in the majority of late-onset ATTRv and by full- length monomers (type B fibrils) in the early-onset V30M ATTRv amyloidosis. Such different compositions contribute to genotypic-phenotypic correlations and impact the sensitiveness of diagnostic procedures such as staining of the tissue biopsy by Congo red, which has a higher affinity for type B fibrils, or non-invasive techniques for amyloid imaging [6].

Amyloid fibrils may cause tissue damage by direct compression or obstruction as it is obvious for carpal tunnel syndrome, vitreous opacities and spinal canal stenosis. The PNS involvement is more likely caused by the neurotoxicity exerted by non-fibrillar oligomers and protofibrils [2]. Diffusible oligomers might bind to the lipid rafts of cell membranes, causing a calcium influx through voltage-gated calcium channels, and to receptors for advanced glycation end products thus interfering with the MAP kinase signalling and inducing endoplasmic-reticulum stress and apoptosis [4].

In ATTRv amyloidosis, the polyneuropathy has a lengthdependent axonal pattern and affects variably both the large and small myelinated as well non-myelinated small fibres. In bioptic specimens, amyloid deposits predominate in the endoneurial blood vessels; deposits and axonal loss have an asymmetric distribution between and within the fascicles. Ultrastructural changes of the endothelial indicate a microangiopathy with a disruption of the blood-nerve barrier which may allow the entry of circulating TTR into the endoneurial space [7]. In the early-onset ATTR-V30M, which manifests with a predominant loss of small fibres, non-myelinating Schwann cells adjacent to amyloid fibrils are distorted and atrophic suggesting a direct effect on cell membranes by the amyloid fibrils. In the late-onset ATTR-V30M, which discloses fewer amyloid deposits, the prevalent involvement of the large myelinated fibres could be rather caused by neurotoxic oligomers [7].

From pathology to symptoms

Amyloid deposits and monomers/oligomers toxicity are the basis of ATTRv clinical presentation. PNS (somatic and autonomic) and heart are the most affected sites. Therefore, peripheral sensory-motor neuropathy, dysautonomia and cardiomyopathy, often in combination, are the common phenotypes [8].

Clinical heterogeneity is only partly explained by genetic mutation differences. The most frequent mutation worldwide, V30M, has either early-onset (in the endemic areas in Portugal and Brazil, mean onset age 33 years; occasionally in other areas including Italy) or late-onset (in Sweden - mean onset age 60 years - in many Japanese cases and in non-endemic countries like Italy), for still unknown reasons [8-10].

Early-onset V30M ATTRv is characterized by a smallfibre neuropathy with neuropathic pain, other positive sensory symptoms, algo-thermal sensory loss at distal limbs; only later touch and deep sensory loss and motor involvement become evident, with a length-dependent distal-to-proximal progression [11]. Autonomic symptoms are common and relevant 
and consist of erectile dysfunction, orthostatic hypotension, reduced sweating, dry eye and mouth, pupillary changes, bladder abnormalities and gastrointestinal dysmotilitycausing early satiety, gastric distension, recurrent nausea and vomiting, diarrhea and/or stipsis [12]. Gastrointestinal dysfunction, also related to direct amyloid infiltration, may play a role in weight loss, a frequent feature of all ATTRv forms [8]. Heart involvement is mainly characterized by arrhythmias, bundle and atrio-ventricular blocks, more rarely sinoatrial blocks, often needing pacemaker positioning [11]. Genders are equally affected and family history is often informative [11].

Late-onset V30M ATTRv has a different clinical picture: the neuropathy affects small and large fibres since the beginning, with sensory loss to all modalities, early muscle wasting and weakness starting from distal sites $[8,10]$. Autonomic involvement is often subtle and undetected if not investigated. Heart dysfunction consists in a hypertrophic infiltrative cardiomyopathy, with preserved ejection fraction, which may be severe and progressive [13]. Given later onset and agedependent penetrance, family history is frequently negative. Males are more commonly affected than females with a 2-3:1 ratio.

The disease course, lethal if left untreated after a mean of 7-10 years, is more rapid in the late-onset variety [8]. The difference between the two forms is likely explained by different types of amyloid deposits: full-length TTR forming regularly disposed fibril with high Congo red affinity in early-onset V30M (type B); a mixture of full-length and cleaved TTR fragments, with irregularly arranged fibrils showing low Congo Red affinity in late-onset V30M (type A) [14].

In non-endemic countries, including Italy, there are many other mutations, some (e.g. $E 89 Q, F 64 L$ ) are also frequent, sharing similarities with the late-onset V30M type, including onset age. T49A and $E 89 Q$ show fast progression; F64L is relatively less rapid; $I 68 \mathrm{~L}$ is predominantly cardiopathic $[9$, $15]$.

Several patients show clinical and/or electrophysiological features of bilateral carpal tunnel syndrome, related to amyloid deposits in the transverse carpal ligament, sometimes preceding by years polyneuropathy onset [16]. Less common atypical phenotypes are large-fibre neuropathy with sensory ataxia, preeminent motor involvement, non-length-dependent pattern with early cranial nerve involvement or upper limb predominance [8]. The progressive neurological impairment leads the untreated patient, who initially has retained walking ability [familial amyloid polyneuropathy (FAP) stage 1], to need assistance for walking (FAP stage 2) and later lose walking ability (FAP stage 3, chairbound/bedridden) [17].

Nephropathy rarely occurs with proteinuria, renal failure, recurrent urinary infections [18]. Ocular involvement is characterized by intraocular amyloid deposits related to the TTR production by the retinal epithelium, causing vitreous opacities, glaucoma and retinal amyloid angiopathy [19]. Few mutations are specifically associated with the exceptional oculoleptomeningeal disease form [20]. TTR production by choroid plexuses is the basis of the rare leptomeningeal variant, with amyloid deposition starting from leptomeningeal vessels and involving - in a centripetal progression along vessels - the brain parenchyma, and manifesting with seizures, hemorrhagic strokes, focal neurological episodes, dementia, ataxia, hydrocephalus, siderosis, calcifications and leptomeningeal enhancement [21].

\section{From neuropathy to diagnosis}

PNS involvement is the presenting complaint in most cases of ATTRv. The main challenge for clinicians in evaluating a neuropathic patient is when to suspect ATTRv in order to catch early the diagnosis. In regions where ATTRv amyloidosis is non-endemic, diagnosis can be delayed by $3-4$ years [8]. The importance of early diagnosis is enormously increased after recent availability of innovative diseasemodifying therapies (see section "Current and emerging therapies"). Thus, bearing in mind the importance of early diagnosis of disease, some clinical, laboratory and instrumental features may raise the suspicion of ATTRv amyloidosis (Fig. 1).

Overall, ATTRv neuropathy is a progressive lengthdependent axonal polyneuropathy involving small (sensory and autonomic) and large (sensory and motor) nerve fibres $[8,22]$.

A preferential and early involvement of small fibres is typical of early-onset V30M ATTRv phenotype [22]. The initial small fibre neuropathy progresses to the involvement of larger fibres (sensory and motor) leading to accumulation of disability and ultimately to death [8].

On the other side, in late-onset ATTRv phenotypes (V30M and most of non-V30M), pathological evidence demonstrates early involvement of all types of nerve fibres even though the impairment of the largest fibres usually overcomes the smallest ones [7, 22].

Therefore, clinicians may face a first scenario including a neuropathic patient complaining of dysautonomia. In such a case, though alternative diagnosis may be considered, genetic testing for ATTRv amyloidosis should not be delayed $[8,23$, 24].

Another scenario, more challenging for clinicians and more common in non-endemic areas, includes sporadic patients with late-onset phenotype that present with a sensory or sensory-motor length-dependent axonal polyneuropathy.

In such a case, electrophysiological features may be similar to several other neuropathies including those dysmetabolic (e.g. diabetes mellitus), toxic, nutritional, paraneoplastic, infectious or late-onset Charcot-Marie-Tooth disease. 
Fig. 1 Suspicion index for diagnosis of ATTRv amyloidosis with PN [adapted from Adams et al. 2019 [8]]. a In early-onset phenotype. b In late-onset phenotype. ATTRv, hereditary amyloidogenic transthyretin amyloidosis; CIDP, chronic inflammatory demyelinating polyradiculoneuropathy, GI gastrointestinal, $\mathrm{OH}$ orthostatic hypotension. Screening test for more common peripheral neuropathy negative
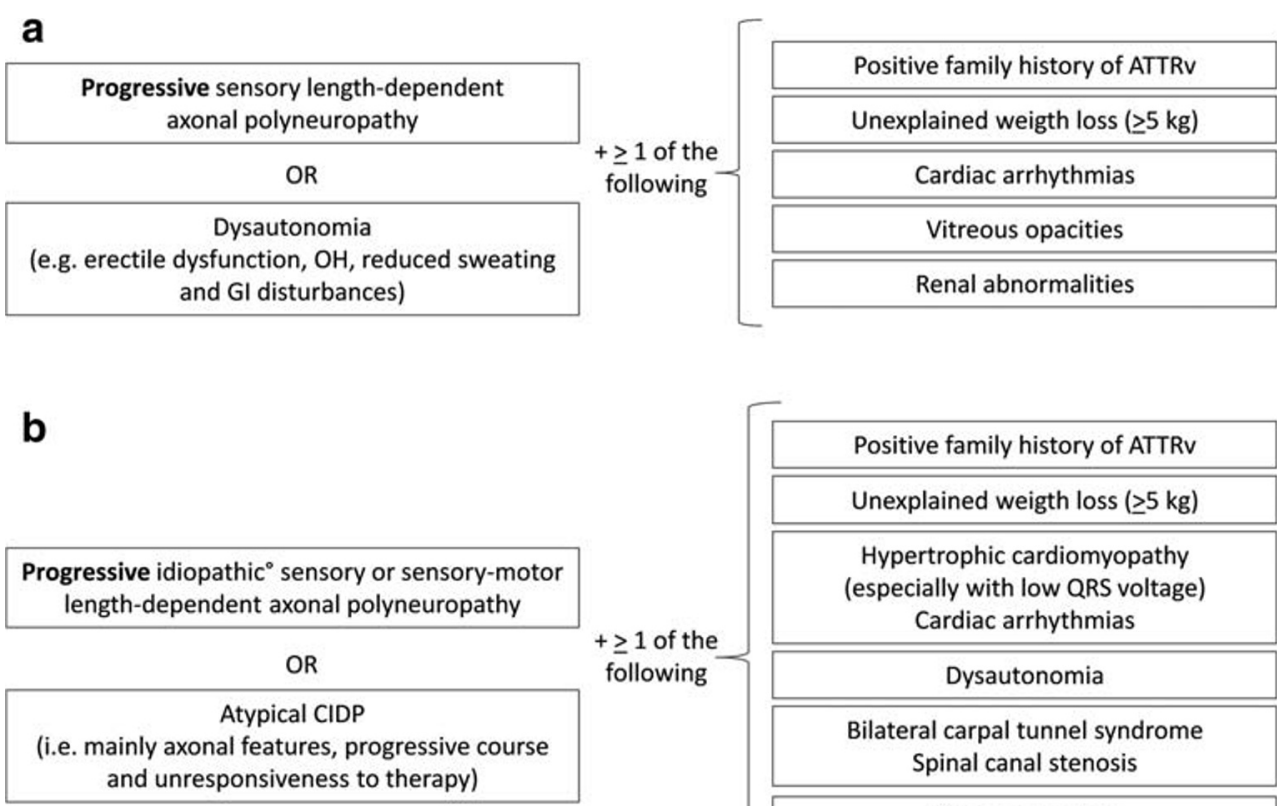

Laboratory screening test for peripheral neuropathy is needed even though comorbidities as diabetes may coexist with ATTRv amyloidosis [25, 26].

The most striking feature of ATTRv neuropathy in differential diagnosis is its progressive course. On average, patients with early-onset form switch from FAP-1 to FAP-2 stage of disease in 5.6 years and from FAP-2 to FAP-3 in 4.8 years. In patients with late-onset form, the progression is even faster and requires 2-4 years for switching from FAP-1 to FAP-2 and 2-3 years from FAP-2 to FAP-3 [27, 28].

This is also important in differential diagnosis from chronic inflammatory demyelinating polyradiculoneuropathy (CIDP) that represents the most common misdiagnosis [29-32]. This comes from the possibility to find in ATTRv patients nerve conduction slowing in range of demyelination [33]. Actually, demyelination occurs in ATTRv neuropathy and myelin alterations are usually in close contact with TTR deposits [8, 30, $31,34]$. Importantly, the chance to detect amyloid deposits in peripheral nerves seems to be related to disease duration in both early- and late-onset ATTRv [8, 22, 34], and accordingly, in late stage of disease, sural nerve findings usually reveal frequent amyloid deposits, conspicuous axonal loss and myelin abnormalities [8, 30, 31, 34]. As well, skin biopsies show, in early stage of disease, a loss of nerve fibres but none or minimal deposition of amyloid with respect to more advanced stage of ATTRv amyloidosis [35, 36].

Therefore, ATTRv patients, usually in more advanced stage of disease, may be mistaken for CIDP, but a careful reading of electrophysiological findings reveals that slow nerve conduction velocity is associated with axonal loss and accordingly with a severe reduction of compound muscle action potential amplitudes [30-32]. Unresponsiveness to therapy (e.g. immunoglobulin) may further raise the suspicion of ATTRv.

Another challenging misdiagnosis encompasses paraproteinemic neuropathies, i.e. amyloid light-chain (AL) amyloidosis and POEMS syndrome [37, 38], that show clinical and electrophysiological similarities with ATTRv neuropathy for coexistence of axonal and demyelinating features as well for multisystem involvement (e.g. heart in AL amyloidosis). Since a paraproteinemia of unknown significance may coexist with ATTRv amyloidosis [38], a hematological evaluation is needed to rule out plasmacellular dyscrasia. In addition, scintigraphy to detect cardiac uptake of bone tracers such as ${ }^{99 \mathrm{~m}}$ Tc-DPD, ${ }^{99 \mathrm{~m}}$ Tc-HMDP, or ${ }^{99 \mathrm{~m}}$ Tc-PYP [39] may be useful in differentiating between monoclonal immunoglobulin light chain and TTR-related cardiac amyloidosis. The possibility of a low sensitivity for specific mutations (e.g. Phe64Leu) should be considered [40]. On the other hand, many studies confirm that VEGF levels could be useful for differentiating POEMS syndrome from amyloidosis [37].

\section{After the diagnosis}

Once the diagnosis of ATTRv amyloidosis has been reached, additional investigations are required to evaluate the extent and severity of organ involvement.

To monitor the polyneuropathy disability, useful tools in clinical practice include the FAP staging system and the polyneuropathy disability (PND) score [17]. However, these 
clinical scales provide only a generic indicator of overall disease status and are not sensitive to track disease progression in the short-term period. Hence, to better evaluate all the aspects of the polyneuropathy, clinical trials have tested different neuropathy impairment score (NIS)-based measures, which provide a better chance to detect a treatment effect. Nevertheless, the NIS score [41], a clinical compound score based on examination of muscle weakness, sensory loss and stretch reflexes in the limbs, and its subset, the NIS-lower limbs (NIS-LL) score, have shown some limitations, requiring gradual modifications.

In a trial published in 2013, the NIS + 7, which combines clinical assessment with seven electrophysiological tests, was used to better characterize and quantify neuropathic impairment [41]. In recent trials, run by Alnylam $[42,43]$ and by Ionis [44], two different variants of the modified NIS $+7(\mathrm{mNIS}+7)$ were used. The mNIS + $7_{\text {Alnylam }}$ and the mNIS $+7_{\text {Ionis}}$, specifically designed to assess disease impairment and progression in hATTR amyloidosis clinical trials, better quantify sensory abnormalities over the whole body, nerve conduction abnormalities and autonomic function [41].

Other useful clinical scales include the Composite Autonomic Symptom Scale-31 (COMPASS-31) questionnaire and the Compound Autonomic Dysfunction Test (CADT) questionnaire for assessment of autonomic symptoms; the Rasch-built Overall Disability Scale (R-ODS) survey for evaluation of activities of daily living; Charcot-MarieTooth Neuropathy scale (CMTNS) and its clinical component CMT Examination Score (CMTES) for monitoring neuropathy progression; the Norfolk Quality of Life-Diabetic Neuropathy (QoL-DN) questionnaire to estimate quality of life; the 6-min walking test, the 10 -m walking test and handgrip strength test (dynamometer) to assess specific motor function [41-45].

Traditional nerve conduction studies are performed to monitor the evolution and the severity of a peripheral neuropathy [46]. Even if skin biopsy still remains the gold standard for the diagnosis of a small fibre neuropathy, evaluation of sudomotor function via electrochemical skin conductance [47], as well as measurement of heart rate variability [48], and testing for orthostatic hypotension can all be useful to investigate an autonomic neuropathy. Sudoscan also proved to be a good tool for monitoring disease progression in late-onset hATTR [47].

Cardiac investigations in ATTRv amyloidosis are mainly aimed at detecting a possible infiltrative (hypertrophic) cardiomyopathy and, above all, any potential serious conduction disorders that may require the implantation of a prophylactic pacemaker to decrease the risk of sudden death. Useful investigations for cardiac assessment include echocardiogram, 24-h Holter monitoring and echocardiography with strain imaging; cardiac magnetic resonance imaging (MRI) and intracardiac electrophysiological studies, even if not always available, are useful when necessary [49].

Cardiac serum biomarkers, specifically brain natriuretic peptide (BNP) or its N-terminal prohormone (NT-proBNP) and cardiac troponins (T or I), are useful and have a prognostic value in amyloid cardiomyopathy [49]. NT-proBNP plasma levels are abnormal even in the early stages of cardiac amyloid infiltration and correlate with left ventricular mass (evaluated on cardiac MRI) and with late gadolinium enhancement, suggesting their utility as a measure of cardiac amyloidosis severity [49]. In addition, high levels of troponin are observed in the most severe forms or in advanced stages of the disease [49].

Once the genetic diagnosis is confirmed, an ophthalmological assessment should be carried out as well. When ocular manifestations are present, the frequency of ophthalmological evaluations varies depending on severity of eye involvement and should include measurement of visual acuity and of intraocular pressure, Schirmer test, ocular fundus and slit-lamp examination [50].

Renal evaluation is also crucial, and usually based on measurement of serum creatinine, proteinuria and microalbuminuria, and on the estimated glomerular filtration rate (eGFR) [46].

Finally, a modified version of the body mass index (mBMI) that corrects for the effect of hypoalbuminaemia provides a marker of nutritional status, which is, to some extent, influenced by the duration and severity of gastrointestinal symptoms and malabsorption in hATTR patients [51].

\section{From presymptomatic testing to carriers}

Protocols for pre-symptomatic genetic testing (PST) of lateonset inherited disorders are available since many years, including that for genetic testing and management of individuals at risk for ATTRv [52-54].

The main purpose of all these protocols is to provide with participants a multidisciplinary team and whole information to protect them against psychosocial consequences of the test results. All PST protocols aim to combine the respect for the autonomy with the maximum benefit, supporting the at-risk individual in the decision-making process and helping her/ him to cope with the results.

All relatives of patients with ATTRv should be considered as possible carriers of the familial mutation and, if they are willing to undergo genetic testing, they should be directed to an expert multidisciplinary team. The whole process should involve teams with expertise in genetic counselling, in providing accurate interpretation of molecular results and in diseasespecific management and follow-up. Due to the possible psychological impact of the test results, a psychologist with expertise in genetic counselling must be available from each team.

Although all adult patient's relatives can undergo ATTRv testing, the potential benefits of PST are greater 
for siblings than for the offspring. In fact, siblings, especially those that are close to the predicted age of disease onset (PADO) [55], are at higher risk for developing clinical disease in the immediate future and deserve the highest priority.

All adult at-risk individuals who may wish to take the test should be given updated and relevant information in order to make an informed voluntary decision. Pre-test counselling should include information not only about the entire testing process, but also about the post-test follow-up.

In general, a minimum interval (e.g. 1 month) between the pre-test counselling session and the decision whether to take the test is habitually recommended to give the person enough time in order to make an informed and autonomous decision. The decision to take the test is the unique choice of the person concerned.

Disclosure of PST results should be done preferably within 4 weeks from blood sample collection. Nevertheless, the proband should have the choice to ask for more time delay before receiving the results or also decide not to be given the results at all [56].

Test result should be given in person to the individual who requested the PST. As a rule, the counselling team should not communicate any information concerning the test and its results to third parties without the explicit permission of the person tested.

If the genetic analysis is positive, the multidisciplinary team must address the subject to the appropriate follow-up program, already discussed before the test, and based on the family mutation and the his/her actual age.

Compared with PST for other late-onset untreatable diseases, the protocol for ATTRv genetic testing has undergone some changes to make it more up-to-date. In fact, in the last years, the ATTRv therapeutic scenario has dramatically changed thanks to the availability of new drugs which are able to treat the disease. Since all therapies are maximally effective in the early stages, the request for PST has largely increased as the possibility to access a therapy balances or outweighs the risk of the psychological consequences of a positive test result. In fact, nowadays, clinicians can offer individuals with positive test result a close monitoring [55], prompting treatment start as soon as minor, but clinically meaningful disease signs, are detected. The PST protocol should be regularly updated in order to offer a flexible approach in accordance with drug discoveries. Attempts to identify new early biomarkers of the progression from an asymptomatic status to the appearance of the first signs of the diseases are currently under investigation [57]. Therefore, clinicians must be prepared to adapt PST to rapid changes in the ATTRv therapeutic landscape to provide the best of care for presymptomatic individuals.

\section{Current and emerging therapies}

Elucidation in molecular pathogenic mechanisms and progress in pharmacological technologies led to an unexpected therapeutic revolution in ATTRv amyloidosis. A wide spectrum of targeted therapies already obtained market access and some others are close to achieve it $[58,59]$.

Until recently drugs, symptomatic relief and orthotopic liver transplant were the only options for ATTRv with the most favourable results in early-onset V30M patients [60].

Recently, new agents have been developed to suppress the production of both amyloidogenic wt and TTRv as well as fibril formation. The landscape of current pharmaceutical approaches for ATTRv includes TTR stabilizer, TTR silencers and TTR disruptors.

\section{TTR stabilizer}

Tafamidis meglumine (Vyndaqel, Pfizer) was the first specific drug approved for stage 1 ATTRv-PN on the basis of an 18-month double-blind placebo-controlled study followed by an open label extension [61]. Later on, several clinical trials supported these findings with newsworthy results in V30M patients and early disease stages [62]. Tafamidis was generally well tolerated, even for long periods [63] and induced reduction of all-cause mortality and cardiovascular related hospitalizations [64]. Tafamidis is now approved in the USA for ATTR cardiomyopathy $(\mathrm{CM})$.

Diflunisal, a non-steroidal anti-inflammatory drug, reduced the progression of neuropathy irrespective of mutation and severity of disease at baseline [65]. Safety and efficacy of diflunisal were reported in respect to neurological and cardiac functions [66], and to autonomic dysfunction [67]. Diflunisal is not approved for ATTRv and can be used only "off-label".

Epigallocatechin-3-gallate (EGCG), the major catechin found in green tea, appears to be able to prevent fibril formation "in vitro" and in cell culture and to disrupt pre-formed fibrils "in vitro" and in animal models [68]. Two studies reported a positive result of green tea consumption in wt- and ATTRv patients with cardiomyopathy $[69,70]$.

Tolcapone stabilizes three leptomeningeal TTR variants, and because it crosses the blood-brain barrier, it has been proposed as a therapy for leptomeningeal amyloidosis [71].

AG10 was well tolerated and induced a significant stabilization of TTR in ATTR-CM [72].

Two-phase three studies, in ATTR-CM and ATTRv-PN, respectively, are still ongoing (ATTRIBUTE-CM, ClinicalTrials.gov Identifier NCT03860935; ATTRibute-PN, ClinicalTrials.gov Identifier: NCT04418024). 


\section{TTR silencers and genome editing}

TTR gene silencing therapy with small interfering RNA (siRNA) or antisense oligonucleotide (ASO) provided a therapeutic revolution, showing evidence that disease progression can be slowed, and perhaps reversed [42-44].

Both patisiran (a siRNA) and inotersen (a secondgeneration ASO) are approved by the EMA and FDA for ATTRv-PN.

A phase $1 / 2$ study with a new GalNac-conjugated ASO (ION-682884) has been initiated (ClinicalTrials. gov Identifier: NCT03728634), and a phase 3 is ongoing.

A phase 3 study with vutrisiran, a new siRNA, is also ongoing. CinicalTrials.gov Identifier: NCT03759379.

CRISPR/Cas9-mediated genome editing approach has been found effective in mouse and rat models [73]. A phase 1 ascending-dose trial is going to be planned.

\section{Fibril disruptors}

Doxycycline and tauroursodeoxycholic acid (TUDCA) are not approved for ATTRv, although they both showed interesting results in experimental studies and combination of oral doxycycline and TUDCA stabilizes the disease for at least 1 year in ATTRv and wt [74, 75]. A phase 3 study of Doxy/TUDCA in cardiac amyloidosis is ongoing. ClinicalTrials.gov Identifier: NCT03481972.

\section{Monoclonal antibodies}

Several monoclonal antibodies against TTR epitopes have been tested "in vitro" as potential new drugs [76].

Dezamizumab is a fully humanized monoclonal IgG1 antiSAP antibody that triggers immunotherapeutic clearance of amyloid. Amyloid load reduction was reported in the liver, spleen, and kidney following his administration in $\mathrm{AL}$ and ATTR amyloidosis [77].

A phase 1 clinical trial with PRX004 is undergoing. ClinicalTrials.gov Identifier: NCT03336580.

\section{Conclusion}

Improved knowledge of pathogenetic mechanisms and the development of efficacious drugs are rapidly changing the history of ATTRv amyloidosis. Thus, the progressive nature of ATTRv emphasizes the need for timely diagnosis and intervention in patients and raises the future challenge of when treating the carriers.
Acknowledgements Open access funding provided by Università degli Studi di Napoli Federico II within the CRUI-CARE Agreement.

\section{Compliance with ethical standards}

Conflict of interest FM received financial grants (honoraria and speaking) from Akcea and Alnylam. GMF acknowledges donations from Akcea to support activities of his Research Unit; financial support from Pfizer, Kedrion and Akcea for participation in National and International Meetings. Participation in Advisory Boards of Vitacess, Alnylam, Akcea. Speaker honorarium from Akcea. ML received financial grants (honoraria and speaking) from Ackea, Alnylam and Pfizer, and travel grants from Ackea, Alnylam, Pfizer. PM was sponsored by Independent Health Educational Grant from Pfizer (2018). AM acknowledges speaker fee and consulting honoraria from Alnylam, Akcea and Pfizer. DP acknowledges donations from Pfizer, financial support from Pfizer, Alnylam for participation in National and International Meetings; participation in Advisory Board of Alnylam and Akcea; speaker honorarium from Alnylam.

Ethical approval Not required.

Informed consent Not required.

Open Access This article is licensed under a Creative Commons Attribution 4.0 International License, which permits use, sharing, adaptation, distribution and reproduction in any medium or format, as long as you give appropriate credit to the original author(s) and the source, provide a link to the Creative Commons licence, and indicate if changes were made. The images or other third party material in this article are included in the article's Creative Commons licence, unless indicated otherwise in a credit line to the material. If material is not included in the article's Creative Commons licence and your intended use is not permitted by statutory regulation or exceeds the permitted use, you will need to obtain permission directly from the copyright holder. To view a copy of this licence, visit http://creativecommons.org/licenses/by/4.0/.

\section{References}

1. Schmidt HH, Waddington-Cruz M, Botteman MF, Carter JA, Chopra AS, Hopps M, Stewart M, Fallet S, Amass L (2018) Estimating the global prevalence of transthyretin familial amyloid polyneuropathy. Muscle Nerve 57:829-837. https://doi.org/10. 1002/mus.26034

2. Merlini G, Bellotti V (2003) Molecular mechanisms of amyloidosis. N Engl J Med 349:583-596. https://doi.org/10.1056/ NEJMra023144

3. Yee AW, Aldeghi M, Blakeley MP, Ostermann A, Mas PJ, Moulin M, de Sanctis D, Bowler MW, Mueller-Dieckmann C, Mitchell EP, Haertlein M, de Groot BL, Boeri Erba E, Forsyth VT (2019) A molecular mechanism for transthyretin amyloidogenesis. Nat Commun 10:925. https://doi.org/10.1038/s41467-019-08609-z

4. Hou X, Aguilar MI, Small DH (2007) Transthyretin and familial amyloidotic polyneuropathy. Recent progress in understanding the molecular mechanism of neurodegeneration. FEBS J 274:16371650. https://doi.org/10.1111/j.1742-4658.2007.05712.x

5. Marcoux J, Mangione PP, Porcari R et al (2015) A novel mechanoenzymatic cleavage mechanism underlies transthyretin amyloidogenesis. EMBO Mol Med 7:1337-1349. https://doi.org/ 10.15252/emmm.201505357 
6. Suhr OB, Lundgren E, Westermark P (2017) One mutation, two distinct disease variants: unravelling the impact of transthyretin amyloid fibril composition. J Intern Med 281:337-347. https:// doi.org/10.1111/joim.12585

7. Koike H, Nakamura T, Nishi R, Ikeda S, Kawagashira Y, Ijima M, Yasuda T, Mukai E, Date Y, Shiomi K, Nakazato M, Katsuno M, Sobue G (2019) Common clinicopathological features in late-onset hereditary transthyretin amyloidosis (Ala97Gly, Va194Gly and Val30Met). Amyloid 26:24-25. https://doi.org/10.1080/ 13506129.2019.1582495

8. Adams D, Koike H, Slama M, Coelho T (2019) Hereditary transthyretin amyloidosis: a model of medical progress for a fatal disease. Nat Rev Neurol 15:387-404. https://doi.org/10.1038/ s41582-019-0210-4

9. Russo M, Obici L, Bartolomei I, Cappelli F, Luigetti M, Fenu S, Cavallaro T, Chiappini MG, Gemelli C, Pradotto LG, Manganelli F, Leonardi L, My F, Sampaolo S, Briani C, Gentile L, Stancanelli C, di Buduo E, Pacciolla P, Salvi F, Casagrande S, Bisogni G, Calabrese D, Vanoli F, di Iorio G, Antonini G, Santoro L, Mauro A, Grandis M, di Girolamo M, Fabrizi GM, Pareyson D, Sabatelli M, Perfetto F, Rapezzi C, Merlini G, Mazzeo A, Vita G (2020) ATTRv amyloidosis Italian Registry: clinical and epidemiological data. Amyloid:1-7. https://doi.org/10.1080/13506129.2020. 1794807

10. Sekijima Y, Ueda M, Koike H, Misawa S, Ishii T, Ando Y (2018) Diagnosis and management of transthyretin familial amyloid polyneuropathy in Japan: red-flag symptom clusters and treatment algorithm. Orphanet J Rare Dis 13:6. https://doi.org/10.1186/ s13023-017-0726-x

11. Conceição I, De Carvalho M (2007) Clinical variability in type I familial amyloid polyneuropathy (Val30Met): comparison between late- and early-onset cases in Portugal. Muscle Nerve 35:116-118. https://doi.org/10.1002/mus.20644

12. Gonzalez-Duarte A (2019) Autonomic involvement in hereditary transthyretin amyloidosis (hATTR amyloidosis). Clin Auton Res 29:245-251. https://doi.org/10.1007/s10286-018-0514-2

13. Rapezzi C, Quarta CC, Obici L, Perfetto F, Longhi S, Salvi F, Biagini E, Lorenzini M, Grigioni F, Leone O, Cappelli F, Palladini G, Rimessi P, Ferlini A, Arpesella G, Pinna AD, Merlini G, Perlini S (2013) Disease profile and differential diagnosis of hereditary transthyretin-related amyloidosis with exclusively cardiac phenotype: an Italian perspective. Eur Heart J 34:520-528. https://doi.org/10.1093/eurheartj/ehs123

14. Suhr OB, Wixner J, Anan I, Lundgren HE, Wijayatunga P, Westermark P, Ihse E (2019) Amyloid fibril composition within hereditary Val30Met (p. Val50Met) transthyretin amyloidosis families. PLoS One 14(2):e0211983. https://doi.org/10.1371/journal. pone. 0211983

15. Parman Y, Adams D, Obici L, Galán L, Guergueltcheva V, Suhr OB, Coelho T, European Network for TTR-FAP (ATTReuNET) (2016) Sixty years of transthyretin familial amyloid polyneuropathy (TTR-FAP) in Europe: where are we now? A European network approach to defining the epidemiology and management patterns for TTR-FAP. Curr Opin Neurol 29(Suppl 1):S3-S13. https://doi. org/10.1097/WCO.0000000000000288

16. Samões R, Taipa R, Valdrez K, Gonçalves I, Melo Pires M, Martins da Silva A, Coelho T (2017) Amyloid detection in the transverse carpal ligament of patients with hereditary ATTR V30M amyloidosis and carpal tunnel syndrome. Amyloid 24:73-77. https://doi. org/10.1080/13506129.2017.1313222

17. Coutinho PM, Lázaro da Silva A, Lopes J et al (1980) Forty years of experience with type I amyloid neuropathy. Review of 483 cases. In: Glenner GG, Pinho e Costa P, Falcao de Freitas A (eds) Amyloid and Amyloidosis. Excerpta Medica, Amsterdam, pp 8898
18. Lobato L, Rocha A (2012) Transthyretin amyloidosis and the kidney. Clin J Am Soc Nephrol 7:1337-1346. https://doi.org/10.2215/ CJN.08720811

19. Dammacco R, Merlini G, Lisch W, Kivelä TT, Giancipoli E, Vacca A, Dammacco F (2020) Amyloidosis and ocular involvement: an overview. Semin Ophthalmol 35:7-26. https://doi.org/10.1080/ 08820538.2019 .1687738

20. Mathieu F, Morgan E, So J, Munoz DG, Mason W, Kongkham P (2018) Oculoleptomeningeal amyloidosis secondary to the rare transthyretin c.381T $>\mathrm{G}$ (p.Ile127Met) mutation. World Neurosurg 111:190-193. https://doi.org/10.1016/j.wneu.2017.12.096

21. Beckius S, Shah K (2018) Intracranial and systemic manifestations of familial leptomeningeal amyloidosis, as seen on CT and MRI. Radiol Case Rep 13:1179-1184. https://doi.org/10.1016/j.radcr. 2018.07.030

22. Koike H, Misu K, Sugiura M, Iijima M, Mori K, Yamamoto M, Hattori N, Mukai E, Ando Y, Ikeda S, Sobue G (2004) Pathology of early- vs late-onset TTR Met30 familial amyloid polyneuropathy. Neurology 63(1):129-138. https://doi.org/10.1212/01.wnl. 0000132966.36437 .12

23. Oaklander AL, Nolano M (2019) Scientific Advances in and Clinical Approaches to Small-Fiber Polyneuropathy: A Review. JAMA Neurol 76:1240. https://doi.org/10.1001/jamaneurol.2019. 2917

24. Pasnoor M, Gordon SA (2019) When should you order genetic testing for patients with cryptogenic neuropathy? Let the data do the talking. Muscle Nerve 59:280-282. https://doi.org/10.1002/ mus. 26409

25. Nold CS, Nozaki K (2020) Peripheral neuropathy: clinical pearls for making the diagnosis. JAAPA 33:9-15

26. Planté-Bordeneuve V, Ferreira A, Lalu T et al (2007) Diagnostic pitfalls in sporadic transthyretin familial amyloid polyneuropathy (TTR-FAP). Neurology 69:693-698. https://doi.org/10.1212/01. wnl.0000267338.45673.f4

27. Adams D, Ando Y, Beirão JM, Coelho T, Gertz MA, Gillmore JD, Hawkins PN, Lousada I, Suhr OB, Merlini G (2020) Expert consensus recommendations to improve diagnosis of ATTR amyloidosis with polyneuropathy. J Neurol. https://doi.org/10.1007/ s00415-019-09688-0

28. Conceição I, González-Duarte A, Obici L, Schmidt HHJ, Simoneau D, Ong ML, Amass L (2016) "Red-flag" symptom clusters in transthyretin familial amyloid polyneuropathy. J Peripher Nerv Syst 21:5-9. https://doi.org/10.1111/jns.12153

29. Cortese A, Vegezzi E, Lozza A, Alfonsi E, Montini A, Moglia A, Merlini G, Obici L (2017) Diagnostic challenges in hereditary transthyretin amyloidosis with polyneuropathy: avoiding misdiagnosis of a treatable hereditary neuropathy. J Neurol Neurosurg Psychiatry 88:457-458. https://doi.org/10.1136/jnnp-2016-315262

30. Lozeron P, Mariani LL, Dodet P, Beaudonnet G, Théaudin M, Adam C, Arnulf B, Adams D (2018) Transthyretin amyloid polyneuropathies mimicking a demyelinating polyneuropathy. Neurology 91(2):e143-e152. https://doi.org/10.1212/WNL. 0000000000005777

31. Mathis S, Magy L, Diallo L, Boukhris S, Vallat JM (2012) Amyloid neuropathy mimicking chronic inflammatory demyelinating polyneuropathy. Muscle Nerve 45:26-31. https://doi.org/10.1002/ mus. 22229

32. Ohashi N, Kodaira M, Morita H, Sekijima Y (2019) Electrophysiological demyelinating features in hereditary ATTR amyloidosis. Amyloid 26:15-23. https://doi.org/10.1080/ 13506129.2018.1564903

33. Joint Task Force of the EFNS and the PNS (2010) European Federation of Neurological Societies/Peripheral Nerve Society Guideline on management of chronic inflammatory demyelinating polyradiculoneuropathy: report of a joint task force of the European Federation of Neurological Societies and the Peripheral Nerve 
Society-First Revision [published correction appears in J Peripher Nerv Syst 2010;15:373]. J Peripher Nerv Syst 15:1-9. https://doi. org/10.1111/j.1529-8027.2010.00245.x

34. Planté-Bordeneuve V, Said G (2011) Familial amyloid polyneuropathy. Lancet Neurol 10:1086-1097. https://doi.org/10. 1016/S1474-4422(11)70246-0

35. Masuda T, Ueda M, Suenaga G, Misumi Y, Tasaki M, Izaki A, Yanagisawa Y, Inoue Y, Motokawa H, Matsumoto S, Mizukami M, Arimura A, Deguchi T, Nishio Y, Yamashita T, Inomata Y, Obayashi K, Ando Y (2017) Early skin denervation in hereditary and iatrogenic transthyretin amyloid neuropathy. Neurology 88: 2192-2197. https://doi.org/10.1212/WNL.0000000000004016

36. Ebenezer GJ, Liu Y, Judge DP, Cunningham K, Truelove S, Carter ND, Sebastian B, Byrnes K, Polydefkis M (2017) Cutaneous nerve biomarkers in transthyretin familial amyloid polyneuropathy. Ann Neurol 82:44-56. https://doi.org/10.1002/ana.24972

37. Briani C, Fabrizi GM, Ruggero S, Torre CD, Ferrarini M, Campagnolo M, Cavallaro T, Ferrari S, Scarlato M, Taioli F, Adami F (2011) Vascular endothelial growth factor helps differentiate neuropathies in rare plasma cell dyscrasias. Muscle Nerve 43: 164-167. https://doi.org/10.1002/mus.21872

38. Phull P, Sanchorawala V, Connors LH, Doros G, Ruberg FL, Berk JL, Sarosiek S (2018) Monoclonal gammopathy of undetermined significance in systemic transthyretin amyloidosis (ATTR). Amyloid 25:62-67. https://doi.org/10.1080/13506129.2018. 1436048

39. Gillmore JD, Maurer MS, Falk RH, Merlini G, Damy T, Dispenzieri A, Wechalekar AD, Berk JL, Quarta CC, Grogan M, Lachmann HJ, Bokhari S, Castano A, Dorbala S, Johnson GB, Glaudemans AWJM, Rezk T, Fontana M, Palladini G, Milani P, Guidalotti PL, Flatman K, Lane T, Vonberg FW, Whelan CJ, Moon JC, Ruberg FL, Miller EJ, Hutt DF, Hazenberg BP, Rapezzi C, Hawkins PN (2016) Nonbiopsy diagnosis of cardiac transthyretin amyloidosis. Circulation 133:2404-2412. https://doi. org/10.1161/CIRCULATIONAHA.116.021612

40. Musumeci MB, Cappelli F, Russo D, Tini G, Canepa M, Milandri A, Bonfiglioli R, di Bella G, My F, Luigetti M, Grandis M, Autore C, Perlini S, Perfetto F, Rapezzi C (2020) Low sensitivity of bone scintigraphy in detecting Phe64Leu mutation-related transthyretin cardiac amyloidosis. JACC Cardiovasc Imaging 13:1314-1321. https://doi.org/10.1016/j.jcmg.2019.10.015

41. Dyck PJB, González-Duarte A, Obici L, Polydefkis M, Wiesman JF, Antonino I, Litchy WJ, Dyck PJ (2019) Development of measures of polyneuropathy impairment in hATTR amyloidosis: from NIS to mNIS + 7. J Neurol Sci 405:116424. https://doi.org/10. 1016/j.jns.2019.116424

42. Adams D, Suhr OB, Dyck PJ, Litchy WJ, Leahy RG, Chen J, Gollob J, Coelho T (2017) Trial design and rationale for APOLLO, a Phase 3, placebo-controlled study of patisiran in patients with hereditary ATTR amyloidosis with polyneuropathy. BMC Neurol 17:181. https://doi.org/10.1186/s12883-017-0948-5

43. Adams D, Gonzalez-Duarte A, O'Riordan WD et al (2018) Patisiran, an RNAi therapeutic, for hereditary transthyretin amyloidosis. N Engl J Med 379:11-21. https://doi.org/10.1056/ NEJMoa1716153

44. Benson MD, Waddington-Cruz M, Berk JL, Polydefkis M, Dyck PJ, Wang AK, Planté-Bordeneuve V, Barroso FA, Merlini G, Obici L, Scheinberg M, Brannagan TH III, Litchy WJ, Whelan C, Drachman BM, Adams D, Heitner SB, Conceição I, Schmidt HH, Vita G, Campistol JM, Gamez J, Gorevic PD, Gane E, Shah AM, Solomon SD, Monia BP, Hughes SG, Kwoh TJ, McEvoy BW, Jung SW, Baker BF, Ackermann EJ, Gertz MA, Coelho T (2018) Inotersen treatment for patients with hereditary transthyretin amyloidosis. N Engl J Med 379:22-31. https://doi.org/10.1056/ NEJMoa1716793
45. Vita GL, Stancanelli C, Gentile L, Barcellona C, Russo M, di Bella G, Vita G, Mazzeo A (2019) 6MWT performance correlates with peripheral neuropathy but not with cardiac involvement in patients with hereditary transthyretin amyloidosis (hATTR). Neuromuscul Disord 29:213-220. https://doi.org/10.1016/j.nmd.2018.11.002

46. Luigetti M, Romano A, Di Paolantonio A, Bisogni G, Sabatelli M (2020) Diagnosis and treatment of hereditary transthyretin amyloidosis (hATTR) polyneuropathy: current perspectives on improving patient care. Ther Clin Risk Manag 16:109-123. https://doi.org/10. 2147/TCRM.S219979

47. Luigetti M, Bisogni G, Romano A, di Paolantonio A, Barbato F, Primicerio G, Rossini PM, Servidei S, Sabatelli M (2018) Sudoscan in the evaluation and follow-up of patients and carriers with TTR mutations: experience from an Italian Centre. Amyloid 25:242246. https://doi.org/10.1080/13506129.2018.1545640

48. Niklasson U, Olofsson BO, Bjerle P (1989) Autonomic neuropathy in familial amyloidotic polyneuropathy. A clinical study based on heart rate variability. Acta Neurol Scand 79:182-187. https://doi. org/10.1111/j.1600-0404.1989.tb03736.x

49. Lehrke S, Steen H, Kristen AV, Merten C, Lossnitzer D, Dengler TJ, Katus HA, Giannitsis E (2009) Serum levels of NT-proBNP as surrogate for cardiac amyloid burden: new evidence from gadolinium-enhanced cardiac magnetic resonance imaging in patients with amyloidosis. Amyloid 16:187-195. https://doi.org/10. 3109/13506120903421538

50. Martins AC, Rosa AM, Costa E, Tavares C, Quadrado MJ, Murta IN (2015) Ocular manifestations and therapeutic options in patients with familial amyloid polyneuropathy: a systematic review. Biomed Res Int 2015:282405-282409. https://doi.org/10.1155/ 2015/282405

51. Suhr O, Danielsson A, Holmgren G, Steen L (1994) Malnutrition and gastrointestinal dysfunction as prognostic factors for survival in familial amyloidotic polyneuropathy. J Intern Med 235:479-485. https://doi.org/10.1111/j.1365-2796.1994.tb01106.x

52. Mandich P, Lamp M, Gotta F, Gulli R, Iacometti A, Marchese R, Bellone E, Abbruzzese G, Ferrandes G (2017) 1993-2014: two decades of predictive testing for Huntington's disease at the Medical Genetics Unit of the University of Genoa. Mol Genet Genomic Med 5:473-480. https://doi.org/10.1002/mgg3.238

53. Paneque M, Félix J, Mendes Á et al (2019) Twenty years of a presymptomatic testing protocol for late-onset neurological diseases in Portugal. Acta Medica Port 32:295-304. https://doi.org/10.20344/ amp. 10526

54. Obici L, Kuks JB, Buades J, Adams D, Suhr OB, Coelho T, Kyriakides T, European Network for TTR-FAP (ATTReuNET) (2016) Recommendations for presymptomatic genetic testing and management of individuals at risk for hereditary transthyretin amyloidosis. Curr Opin Neurol 29(Suppl 1):S27-S35. https://doi.org/ 10.1097/WCO.0000000000000290

55. Conceição I, Damy T, Romero M, Galán L, Attarian S, Luigetti M, Sadeh M, Sarafov S, Tournev I, Ueda M (2019) Early diagnosis of ATTR amyloidosis through targeted follow-up of identified carriers of TTR gene mutations. Amyloid 26:3-9. https://doi.org/10.1080/ 13506129.2018.1556156

56. Benatar M, Stanislaw C, Reyes E, Hussain S, Cooley A, Fernandez MC, Dauphin DD, Michon SC, Andersen PM, Wuu J (2016) Presymptomatic ALS genetic counseling and testing: experience and recommendations. Neurology 86:2295-2302. https://doi.org/ 10.1212/WNL.0000000000002773

57. Vita GL, Aguennouz M, Polito F et al (2020) Circulating microRNAs profile in patients with transthyretin variant amyloidosis. Front Mol Neurosci 13:102. https://doi.org/10.3389/fnmol. 2020.00102

58. Vita G, Vita GL, Stancanelli C, Gentile L, Russo M, Mazzeo A (2019) Genetic neuromuscular disorders: living the era of a 
therapeutic revolution. Part 1: peripheral neuropathies. Neurol Sci 40:661-669. https://doi.org/10.1007/s10072-019-03778-7

59. Müller ML, Butler J, Heidecker B (2020) Emerging therapies in transthyretin amyloidosis - a new wave of hope after years of stagnancy? Eur J Heart Fail 22:39-53. https://doi.org/10.1002/ejhf. 1695

60. Benson MD (2013) Liver transplantation and transthyretin amyloidosis. Muscle Nerve 47:157-162. https://doi.org/10.1002/mus. 23521

61. Coelho T, Maia LF, da Silva AM, Cruz MW, Planté-Bordeneuve V, Suhr OB, Conceiçao I, Schmidt HHJ, Trigo P, Kelly JW, Labaudinière R, Chan J, Packman J, Grogan DR (2013) Longterm effects of tafamidis for the treatment of transthyretin familial amyloid polyneuropathy. J Neurol 260:2802-2814. https://doi.org/ 10.1007/s00415-013-7051-7

62. Cortese A, Vita G, Luigetti M, Russo M, Bisogni G, Sabatelli M, Manganelli F, Santoro L, Cavallaro T, Fabrizi GM, Schenone A, Grandis M, Gemelli C, Mauro A, Pradotto LG, Gentile L, Stancanelli C, Lozza A, Perlini S, Piscosquito G, Calabrese D, Mazzeo A, Obici L, Pareyson D (2016) Monitoring effectiveness and safety of Tafamidis in transthyretin amyloidosis in Italy: a longitudinal multicenter study in a non-endemic area. J Neurol 263: 916-924. https://doi.org/10.1007/s00415-016-8064-9

63. Barroso FA, Judge DP, Ebede B, Li H, Stewart M, Amass L, Sultan MB (2017) Long-term safety and efficacy of tafamidis for the treatment of hereditary transthyretin amyloid polyneuropathy: results up to 6 years. Amyloid 24:194-204. https://doi.org/10.1080/ 13506129.2017.1357545

64. Maurer MS, Schwartz JH, Gundapaneni B, Elliott PM, Merlini G, Waddington-Cruz M, Kristen AV, Grogan M, Witteles R, Damy T, Drachman BM, Shah SJ, Hanna M, Judge DP, Barsdorf AI, Huber P, Patterson TA, Riley S, Schumacher J, Stewart M, Sultan MB, Rapezzi C, ATTR-ACT Study Investigators (2018) Tafamidis treatment for patients with transthyretin amyloid cardiomyopathy. N Eng1 J Med 379:1007-1016. https://doi.org/10.1056/ NEJMoa1 805689

65. Berk JL, Suhr OB, Obici L, Sekijima Y, Zeldenrust SR, Yamashita T, Heneghan MA, Gorevic PD, Litchy WJ, Wiesman JF, Nordh E, Corato M, Lozza A, Cortese A, Robinson-Papp J, Colton T, Rybin DV, Bisbee AB, Ando Y, Ikeda S, Seldin DC, Merlini G, Skinner M, Kelly JW, Dyck PJ, Diflunisal Trial Consortium (2013) Repurposing diflunisal for familial amyloid polyneuropathy: a randomized clinical trial. JAMA 310:2658-2667. https://doi.org/10. 1001/jama.2013.283815

66. Sekijima Y, Tojo K, Morita H, Koyama J, Ikeda S (2015) Safety and efficacy of long-term diflunisal administration in hereditary transthyretin (ATTR) amyloidosis. Amyloid 22:79-83. https://doi. org/10.3109/13506129.2014.997872

67. Takahashi R, Ono K, Shibata S, Nakamura K, Komatsu J, Ikeda Y, Ikeda T, Samuraki M, Sakai K, Iwasa K, Kayano D, Yamada M (2014) Efficacy of diflunisal on autonomic dysfunction of lateonset familial amyloid polyneuropathy (TTR Val30Met) in a Japanese endemic area. J Neurol Sci 345:231-235. https://doi.org/ 10.1016/j.jns.2014.07.017

68. Ferreira N, Saraiva MJ, Almeida MR (2012) Epigallocatechin-3gallate as a potential therapeutic drug for TTR-related amyloidosis: "in vivo" evidence from FAP mice models. PLoS One 7:e29933. https://doi.org/10.1371/journal.pone.0029933

69. Kristen AV, Lehrke S, Buss S, Mereles D, Steen H, Ehlermann P, Hardt S, Giannitsis E, Schreiner R, Haberkorn U, Schnabel PA, Linke RP, Röcken C, Wanker EE, Dengler TJ, Altland K, Katus HA (2012) Green tea halts progression of cardiac transthyretin amyloidosis: an observational report. Clin Res Cardiol 101:805-813. https://doi.org/10.1007/s00392-012-0463-z

70. aus dem Siepen F, Buss SJ, Andre F et al (2015) Extracellular remodeling in patients with wild-type amyloidosis consuming epigallocatechin-3-gallate: preliminary results of T1 mapping by cardiac magnetic resonance imaging in a small single center study. Clin Res Cardiol 104:640-647. https://doi.org/10.1007/s00392015-0826-3

71. Pinheiro F, Varejão N, Esperante $S$, Santos J, Velázquez-Campoy A, Reverter D, Pallarès I, Ventura S (2020) Tolcapone, a potent aggregation inhibitor for the treatment of familial leptomeningeal amyloidosis. FEBS J. https://doi.org/10.1111/febs.15339

72. Fox JC, Hellawell JL, Rao S, O'Reilly T, Lumpkin R, Jernelius J, Gretler D, Sinha U (2020) First-in-human study of AG10, a novel, oral, specific, selective, and potent transthyretin stabilizer for the treatment of transthyretin amyloidosis: a phase 1 safety, tolerability, pharmacokinetic, and pharmacodynamic study in healthy adult volunteers. Clin Pharmacol Drug Dev 9:115-129. https://doi.org/10. 1002/cpdd.700

73. Finn JD, Smith AR, Patel MC, Shaw L, Youniss MR, van Heteren J, Dirstine T, Ciullo C, Lescarbeau R, Seitzer J, Shah RR, Shah A, Ling D, Growe J, Pink M, Rohde E, Wood KM, Salomon WE, Harrington WF, Dombrowski C, Strapps WR, Chang Y, Morrissey DV (2018) A single administration of CRISPR/Cas9 lipid nanoparticles achieves robust and persistent in vivo genome editing. Cell Rep 22:2227-2235. https://doi.org/10.1016/j.celrep. 2018.02.014

74. Cardoso I, Martins D, Ribeiro T, Merlini G, Saraiva MJ (2010) Synergy of combined doxycycline/TUDCA treatment in lowering transthyretin deposition and associated biomarkers: studies in FAP mouse models. J Transl Med 8:74. https://doi.org/10.1186/14795876-8-74

75. Obici L, Cortese A, Lozza A, Lucchetti J, Gobbi M, Palladini G, Perlini S, Saraiva MJ, Merlini G (2012) Doxycycline plus tauroursodeoxycholic acid for transthyretin amyloidosis: a phase II study. Amyloid 19(Suppl 1):34-36. https://doi.org/10.3109/ 13506129.2012.678508

76. Ando Y, Ueda M (2017) Antibody therapy for transthyretin-related hereditary amyloid polyneuropathy: another therapeutic option. Amyloid 24:113-114. https://doi.org/10.1080/13506129.2017. 1293514

77. Richards DB, Cookson LM, Barton SV et al (2018) Repeat doses of antibody to serum amyloid $\mathrm{P}$ component clear amyloid deposits in patients with systemic amyloidosis. Sci Transl Med 10(422): eaan3128. https://doi.org/10.1126/scitranslmed.aan3128

Publisher's note Springer Nature remains neutral with regard to jurisdictional claims in published maps and institutional affiliations. 